\title{
The thyroid hormone antagonizes STAT3-dependent transcription in hepatocarcinoma cells
}

The known functions of the thyroid hormones in the liver have expanded from their well-known roles in regulating metabolism to also participate in liver regeneration,



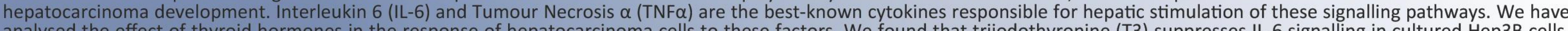

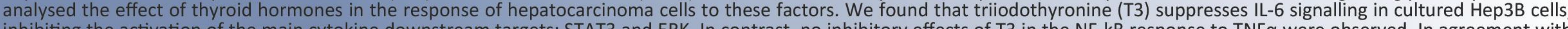

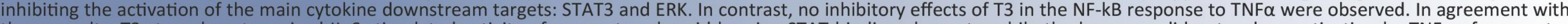

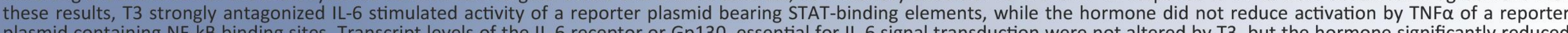

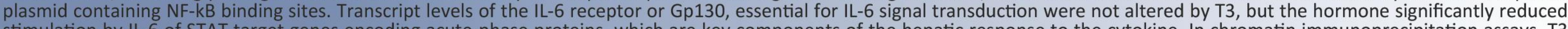

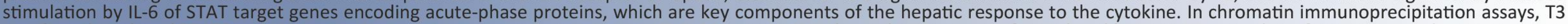

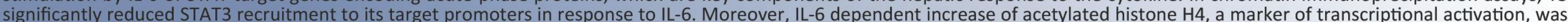

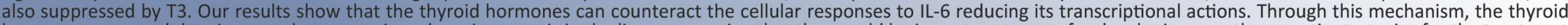

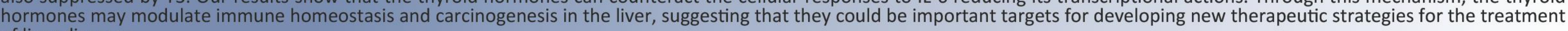
of liver diseases.

T3 antagonizes IL-6 but not TNF $\alpha$ signaling in hepatocarcinoma cells
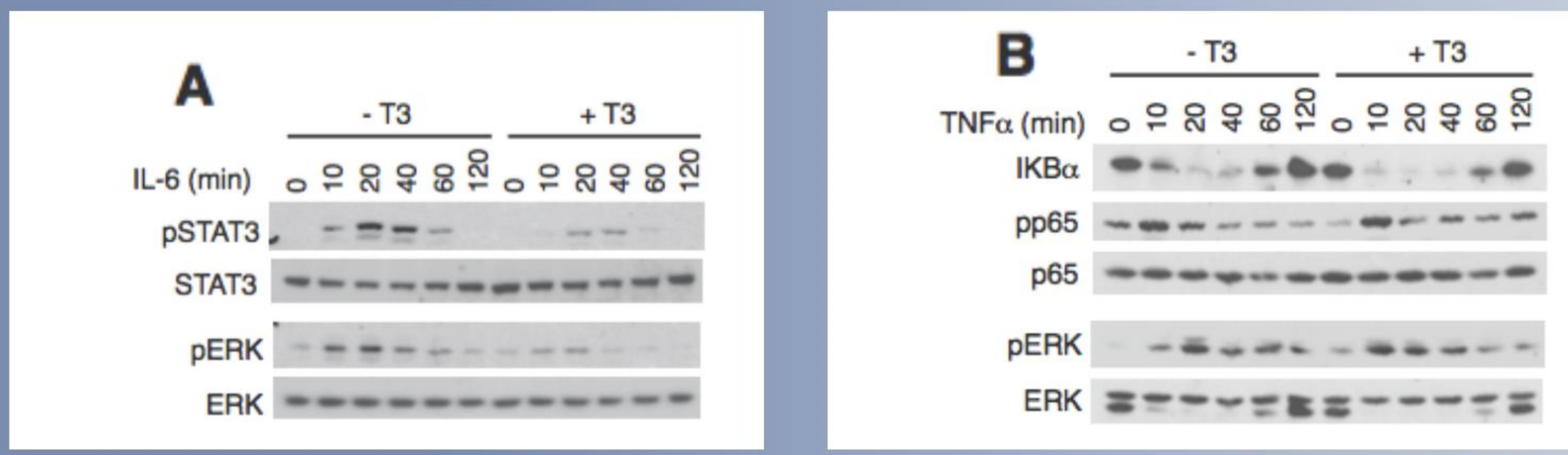

Figure 1. A. Proteins were extracted from Hep3B cells pretreated with $5 \mathrm{nM}$ T3 in $10 \%$ thyroid hormone-depleted serum for $36 \mathrm{~h}$ and then treated with $10 \mathrm{ng} / \mathrm{ml} \mathrm{IL-6}$ for times ranging from 0 to $120 \mathrm{~min}$. The levels of phosphorylated and total STAT3 and ERK were assessed by Western blot. B. Western blot analysis of the indicated proteins of the NF-KB pathway in cells pretreated with T3 and then incubated with $10 \mathrm{ng} / \mathrm{ml} \mathrm{TNF \alpha} \mathrm{for}$ varying times.

T3 represses transcriptional activation of STAT3-dependent genes by IL-6

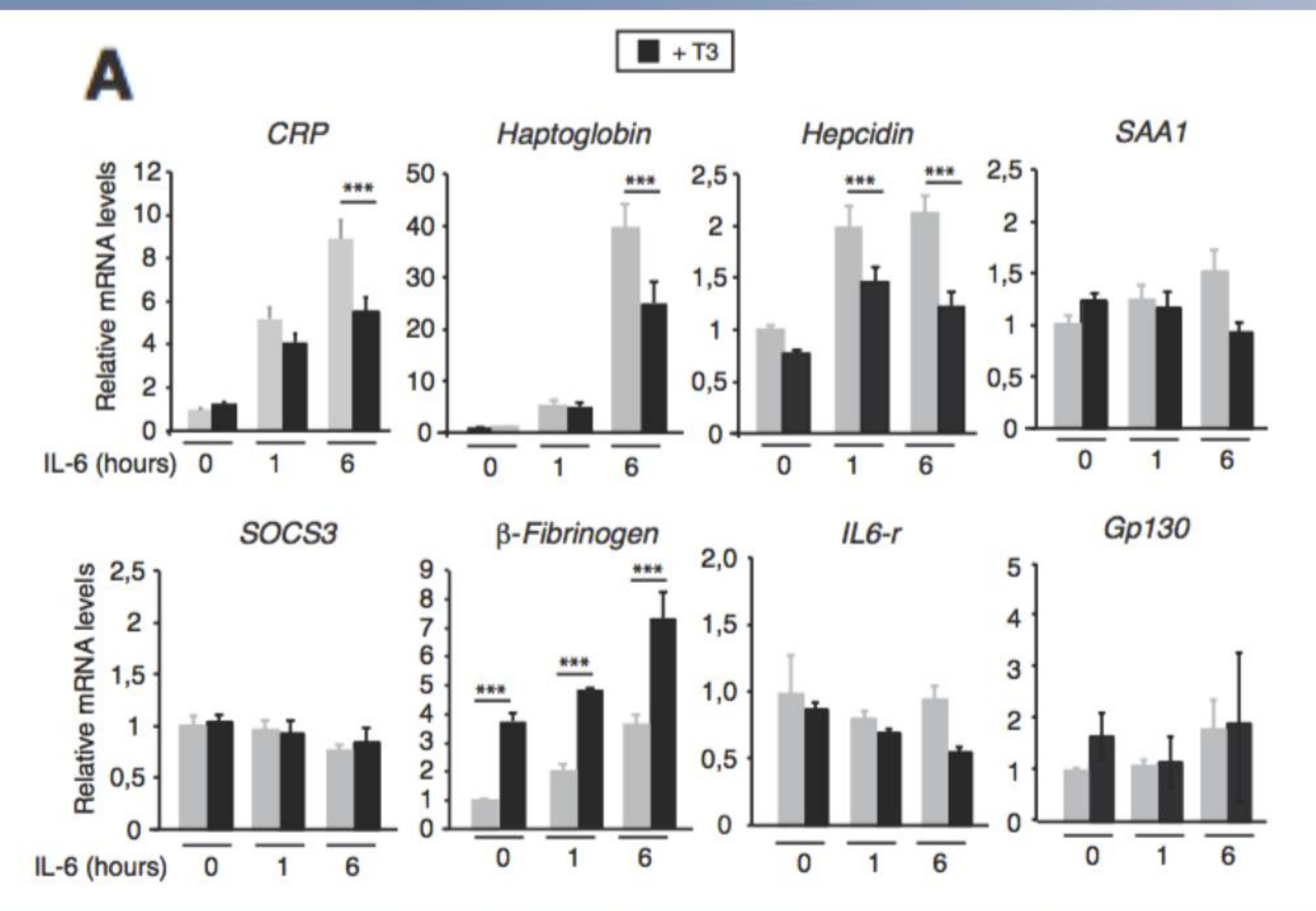

Figure 3. A. Levels of the indicated transcripts (means \pm s.d) determined in Hep3B cells treated with $5 \mathrm{nM}$ T3 for $36 \mathrm{~h}$ and with IL-6 for 0,1 and $6 \mathrm{~h}$. Significance of post-hoc ANOVA test between cells treated with and without $\mathrm{T} 3$ is indicated.
T3 reduces STAT3 recruitment and histone 4 acetylation at IL-6 responsive promoters

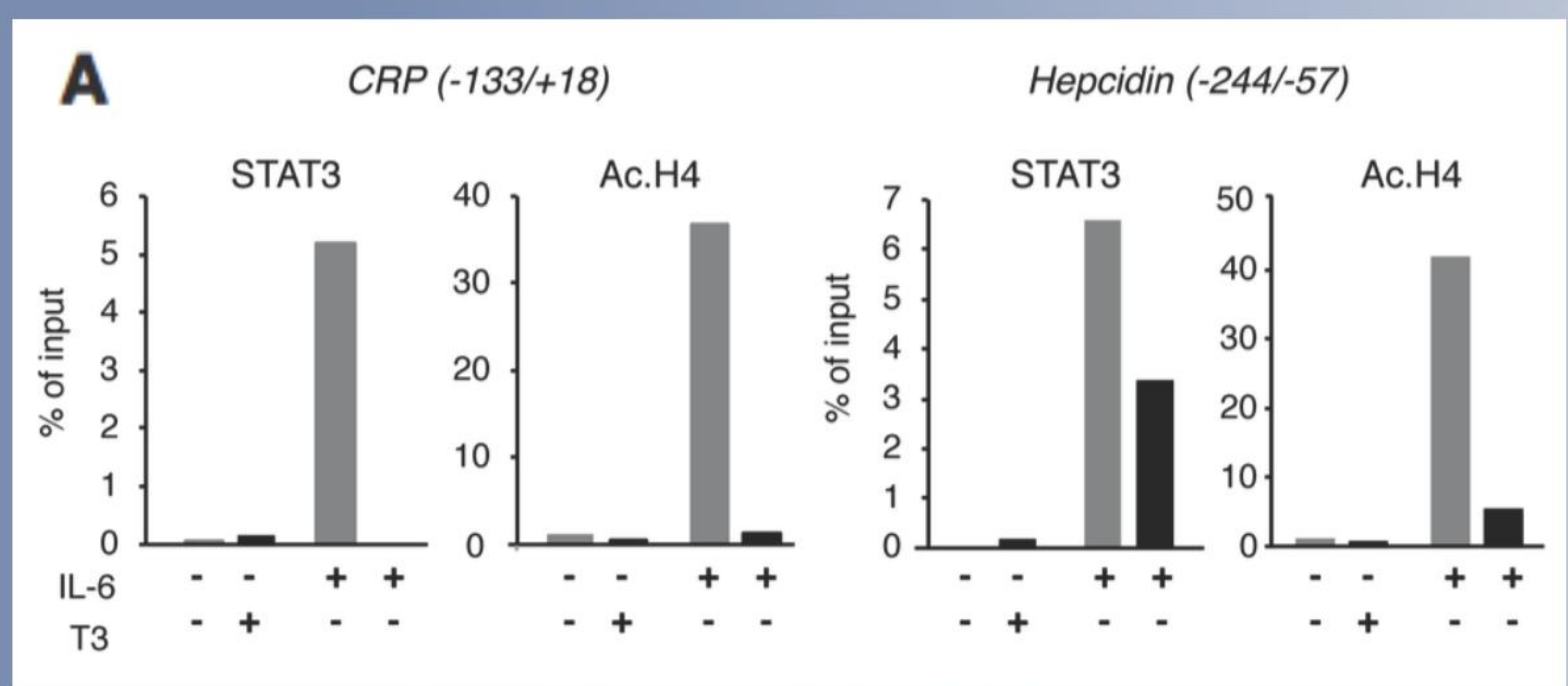

Figure 4 A. Chromatin immunoprecipitation (ChIP) assays with the indicated regions of the CRP and Hepcidin genes and antibodies against STAT3 or acetylated H4 (AC.H4). Data are expressed of \% of the input after subtracting the values obtained with a control lgG.
T3 inhibits STAT3 transcriptiona activity but does not affect NF-k $\beta$ activity

A Stat3-luc

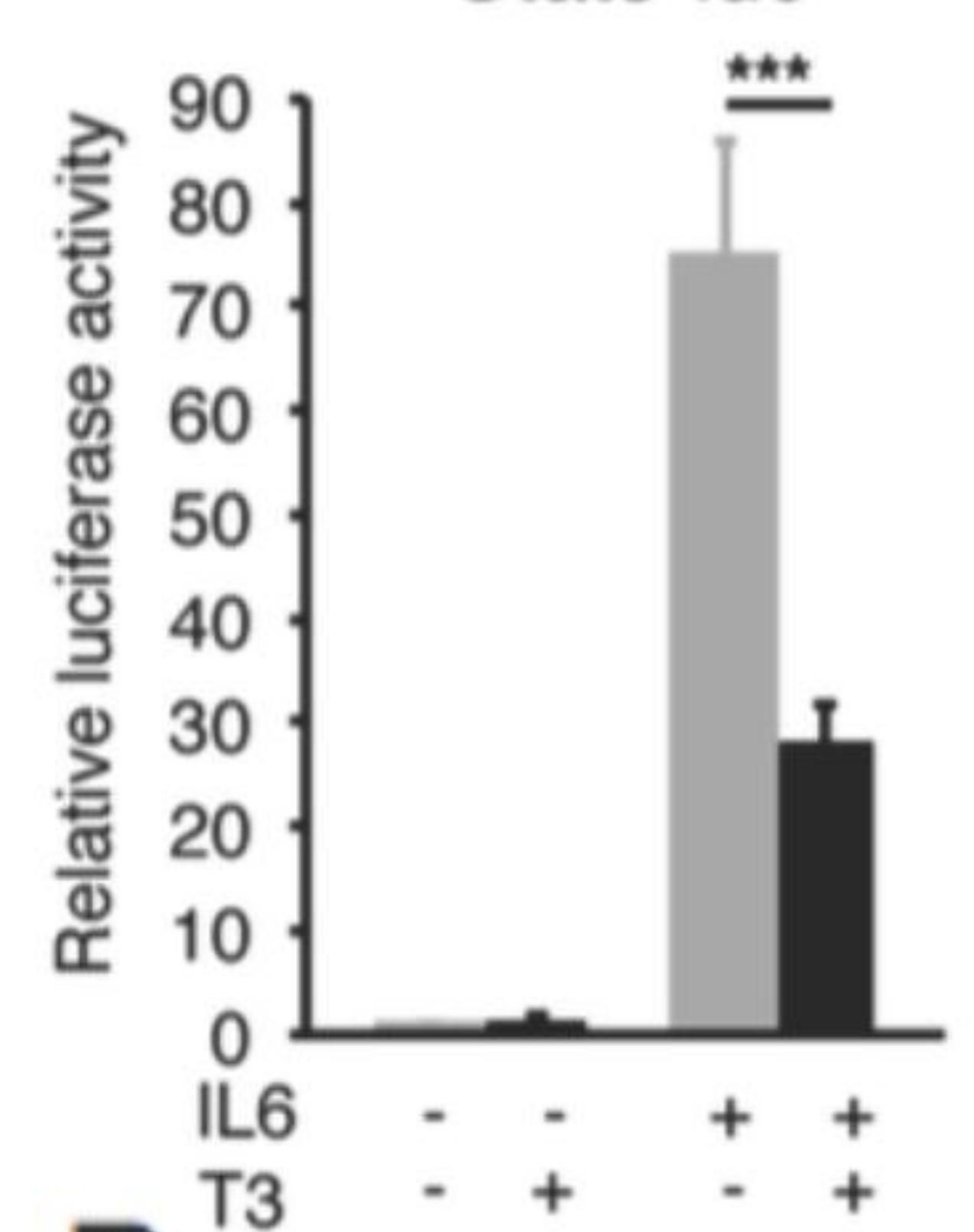

B

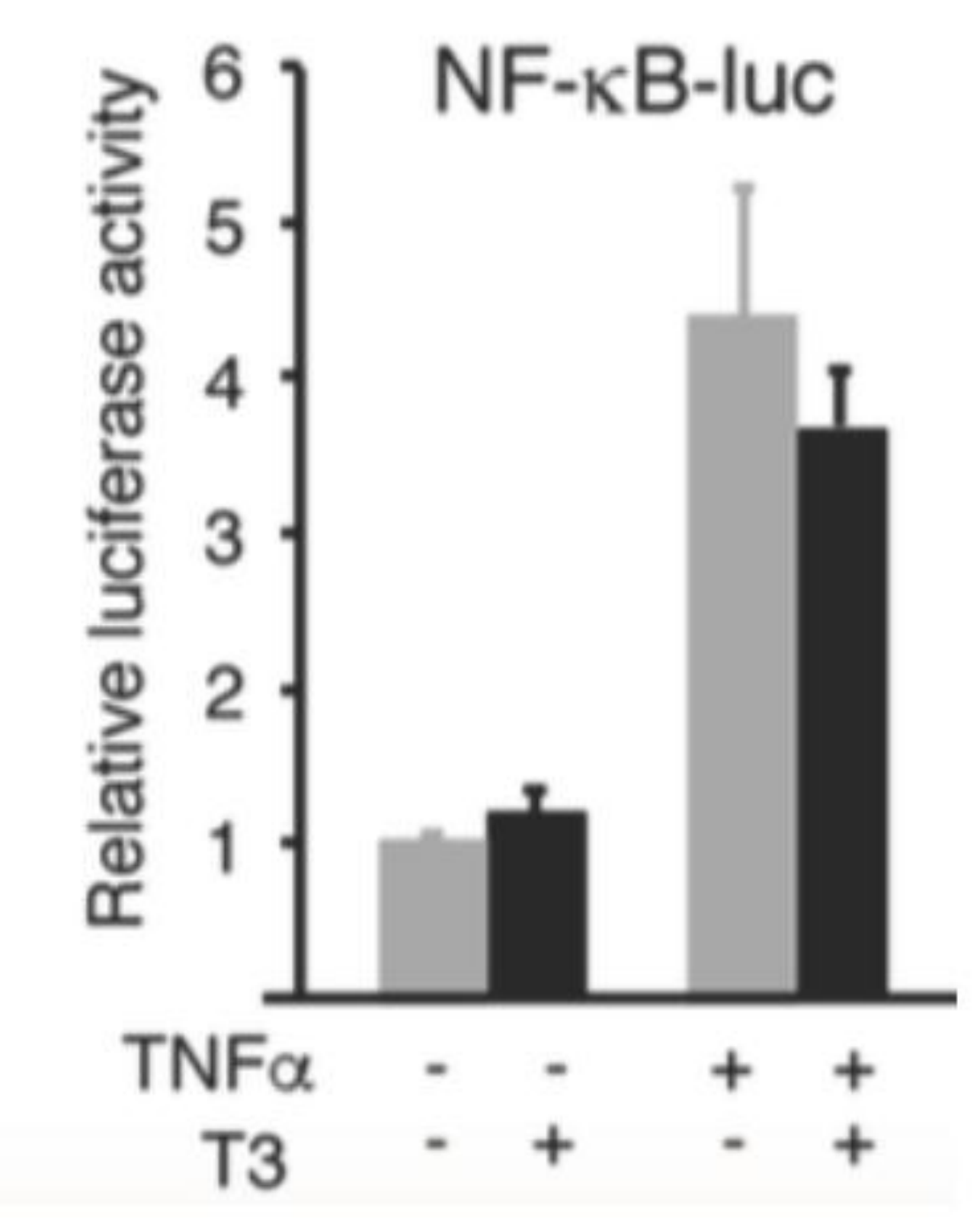

Figure 2. A. Hep3B cells were transiently transfected with a reporter plasmid containing STAT binding sites and incubated in the presence and absence of T3 for $36 \mathrm{~h}$ and with IL-6 for the last $5 \mathrm{~h}$. B. Luciferase activity in cells transfected with a reporter plasmid containing $\mathrm{NF}-\mathrm{k} \beta$ binding sites and treated with $\mathrm{T} 3$ for $36 \mathrm{~h}$ and/or TNF $\alpha$ for the last $5 \mathrm{~h}$.

\section{CONCLUSIONS}

- The thyroid hormone T3, suppresses IL-6 signaling, inhibiting the activation of the main downstream targets of the cytokine: STAT3 and ERK.

- T3 has no effect on the NF-KB response to TNF $\alpha$.

- The hormone antagonizes the induction of acute-phase proteins (APP) genes by the cytokine (IL-6).

- Transcripts of the IL-6 receptor or Glycoprotein 130 (Gp130), the common subunit of the type I cytokine receptors, essential for IL-6 signal transduction were not altered by $\mathrm{T3}$.

- T3 reduces STAT3 binding to IL-6 responsive promoters.

The thyroid hormones can antagonize IL-6 dependent transcription, potentially modulating the effects of the cytokine on immune responses and carcinogenesis . 